\title{
Myths and Facts About Breast Feeding in Primary Health Care Center in Sohag, Egypt
}

\author{
Abdel M. Megaied Bioumy, Mohammed Abo-Alwafa Aladawy, Wafaa Adel Shehata* \\ Department of Pediatrics and Neonatology, Faculty of Medicine, Al-Azhar University (Assiut), Egypt \\ *Corresponding author: Wafaa Adel Shehata, Mobile: (+20) 01119966826, E-Mail: m_adel_20102020@yahoo.com
}

\begin{abstract}
Background: Environment influences infant feeding decisions of mothers, which have influence on growth, development, health and nutrition of infants and children.

Objectives: To assess the maternal knowledge and practices towards breast-feeding among mothers in Sohag. To correlate breast-feeding practices with maternal education, parity, mode of delivery, socioeconomic status and employment.

Patients and methods: This cross-sectional study included 500 mothers of infants attending some primary health centers from $1^{\text {st }}$ January to $30^{\text {th }}$ November 2020. Data were collected using a self-administered standardized questionnaire.

Results: Information present in this questionnaire were taken from 500 mothers, their information was founded to be taken from what friends (33\%), media (10\%) and primitives (57\%). 52\% of mothers knew that breast feeding was used as contraceptives. $63 \%$ of mothers agreed that babies breast fed naturally were healthier than those who breast feed artificially. $67 \%$ of mothers agreed that breast milk is useful but not satisfy the nutritional needs to sustain optimal growth beyond 6 months not due to decrease quality of breast milk but increased demand. Breast-feeding is related to educational level, parity, and socioeconomic status, in which (58\%) and (80) of mothers had moderate educational level and moderate socioeconomic level respectively. Despite $61 \%$ of mothers disagree with the concept that they should stop nursing after only one year. Only $20 \%$ of them agreed to give bottle-feeding as complementary.

Conclusion: It is really an encouraging observation that majority of the mothers had good knowledge and a positive attitude towards breast-feeding. Majority of the mothers fed the baby colostrum. Late initiation of breast-feeding has implications for health education programs and neonatal feeding strategies.
\end{abstract}

Keywords: Breast feeding; Knowledge; Practices; Colostrum; Duration of breast feeding, Bottle-feeding.

\section{INTRODUCTION}

Breast-feeding called nursing means introduction of breast milk to infant. Breast-feeding provides optimal and complete nutrition for newborn babies and the health risks associated with infant formula feeding are increasingly documented ${ }^{(\mathbf{1})}$.

During infancy, breast-feeding protects against infectious disease, by the time, breast-feeding is associated with several benefits such as C.V.S, IQ, and atopy ${ }^{(2)}$.

It is known that breast-feeding rates vary by demographic and socioeconomic factors that affect its initiation and duration. Studies showed that characteristics such as increasing maternal age, education, income and being a non-smoker are associated with elevated rates of breast-feeding ${ }^{(3)}$.

The first two years of life are serious for a child's growth and development. Any damage caused by nutritional deficiencies during this period could lead to impaired cognitive development, compromised educational achievement and low economic productivity. Various factors such as sub-optimal breastfeeding and complementary feeding practices have been identified.

These are influenced by maternal characteristics such as age, marital status, occupation, education level, antenatal, maternity health care, health education and media exposure, socio-economic status and area of residence and child's characteristics including birth weight, method of delivery, birth order, and the use of pacifier ${ }^{(4)}$. Breast-feeding practices are influenced by demographic, social, cultural and psychological factors (5).

The World Health Organization (WHO) recommends exclusive breast-feeding for six months. The estimated reduction of infant mortality by promoting exclusive breast-feeding is $13 \%$. Non-exclusive breast-feeding rather than exclusive breast-feeding can increase the risk of dying due to diarrhea and pneumonia among 0-5 month old infants by more than two-fold ${ }^{(4)}$.

Despite awareness of advantages of breastfeeding, its rates often fall short of recommended practice. Importance of exclusive breast-feeding (EBF) is well established particularly in poor environments where early introduction of other milk is of particular concern because of the risk of pathogens, contamination and over dilution of milk leading to increased risks of morbidity and undernutrition. However, the rates of early initiation, exclusive breast-feeding and timing of complementary feeds are far from desirable ${ }^{(\boldsymbol{\sigma})}$.

This study aimed to assess the knowledge, practices towards breast-feeding and to find these factors, which influence the breast-feeding among mothers in Sohag. Information about breast-feeding practices in the rural population will be useful for interventional programs. 


\section{PATIENTS AND METHODS}

Mothers of infants attending Primary Health Centre, for immunization or ill health were included in this study. Informed consents were taken from the mothers, who were willing to participate in the study and interviewed regarding Breast-feeding knowledge and practices.

Study Period: $1^{\text {st }}$ January to $30^{\text {th }}$ November 2020 .

Sample Size Calculation: Sample size calculation was done randomly selected by questionnaires to 500 mothers.

Study Design: It is a cross-sectional, questionnairebased study done in the setting of Primary Health Centre.

\section{Method of Data Collection:}

Mothers of children aged between 1 day to 2 years visiting Primary Health Centre were included. A face-to-face interview using a pre-designed, selfadministered, standardized questionnaire regarding knowledge and practices of Breast-feeding was conducted. The questionnaire, included data about maternal age, parity, education, employment and socioeconomic status, Health education was given to all the mothers interviewed regarding the advantages of Breast-feeding.

Inclusion Criteria: All mothers of infants visiting primary health care centers in many areas in Sohag.

\section{Exclusion Criteria:}

Conditions where Breast-feeding is contraindicated like galactosemia, mother suffering from cancer, active tuberculosis and psychoses.

\section{Ethical consent:}

An approval of the study was obtained from AlAzhar University Academic and Ethical Committee. Every patient signed an informed written consent for acceptance of the study. This work has been carried out in accordance with The Code of Ethics of the World Medical Association (Declaration of Helsinki) for studies involving humans.

\section{Statistical analysis}

Recorded data were analyzed using the statistical package for social sciences, version 20.0 (SPSS Inc., Chicago, Illinois, USA). Quantitative data were expressed as mean \pm standard deviation (SD). Qualitative data were expressed as frequency and percentage. Independentsamples t-test of significance was used when comparing between two means. Chi-square $\left(\mathrm{x}^{2}\right)$ test of significance was used in order to compare proportions between two qualitative parameters. The confidence interval was set to $95 \%$ and the margin of error accepted was set to $5 \%$. The p-value was considered significant as follows: Pvalue $\leq 0.05$ was considered significant. $\mathrm{P}$-value $<0.001$ was considered as highly significant. P-value $>0.05$ was considered insignificant.

RESULTS

Table (1): Some demographic characteristics of mothers involved in this study

\begin{tabular}{|c|c|c|c|c|}
\hline \multirow{3}{*}{ Type of feeding } & & & No. & $\%$ \\
\hline & Breast-feeding & \multicolumn{2}{|c|}{400} & 90.0 \\
\hline & Breast-feeding, bottle-feeding & \multicolumn{2}{|c|}{100} & 10.0 \\
\hline \multirow{2}{*}{\multicolumn{2}{|c|}{ Number of pregnancies? }} & \multicolumn{2}{|c|}{ Range } & Mean \pm SD \\
\hline & & \multicolumn{2}{|c|}{$1-11$} & $3.67 \pm 2.251$ \\
\hline \multicolumn{2}{|c|}{ Number of deliveries? } & \multicolumn{2}{|c|}{$1-11$} & $3.48 \pm 2.257$ \\
\hline \multicolumn{2}{|c|}{ Number of twins? } & \multicolumn{2}{|c|}{$0-2$} & $0.25 \pm 0.555$ \\
\hline \multirow{2}{*}{\multicolumn{2}{|c|}{ History of consanguinity }} & No & 300 & 60 \\
\hline & & Yes & 200 & 40.0 \\
\hline \multirow{3}{*}{\multicolumn{2}{|c|}{ History of contraceptives }} & IUD & 30 & 6.0 \\
\hline & & No & 200 & 40.0 \\
\hline & & Pills & 270 & 54.0 \\
\hline \multirow{2}{*}{\multicolumn{2}{|c|}{ Economic status }} & Low & 100 & 20 \\
\hline & & Moderate & 400 & 80 \\
\hline \multirow{3}{*}{\multicolumn{2}{|c|}{ Level of education }} & High & 60 & 12.0 \\
\hline & & Low & 150 & 30,0 \\
\hline & & Moderate & 290 & 58.0 \\
\hline \multicolumn{2}{|c|}{ History of genetic diseases } & No & 500 & 100.0 \\
\hline \multicolumn{2}{|c|}{ History of contraindication of Breast feeding } & No & 500 & 100.0 \\
\hline \multicolumn{2}{|c|}{ Type of bottle feeding if present } & No & 100 & 20,0 \\
\hline \multirow{3}{*}{\multicolumn{2}{|c|}{ Source of information present in this questionnaire }} & Friends & 130 & 26.0 \\
\hline & & Media & 100 & 20.0 \\
\hline & & Primitives & 270 & 54.0 \\
\hline
\end{tabular}


Table (2): Questions at which facts more than myths

\begin{tabular}{|c|c|c|c|}
\hline & & No. & $\%$ \\
\hline \multirow[t]{2}{*}{ Is Breast feeding socially unacceptable in our time? } & False & 310 & 62 \\
\hline & True & 190 & 38 \\
\hline \multirow{2}{*}{ Should a baby be awakened for breast-feeding to sleep? } & False & 315 & 63.0 \\
\hline & True & 185 & 37.0 \\
\hline \multirow{2}{*}{ Are babies' breastfed naturally healthier than those who are fed artificially? } & False & 185 & 37.0 \\
\hline & True & 315 & 63.0 \\
\hline \multirow[t]{2}{*}{ Does breast feeding lead to a decrease in breast milk production? } & False & 375 & 75.0 \\
\hline & True & 125 & 25.0 \\
\hline \multirow[t]{2}{*}{ Should the mother breastfeed her child 4-6 times only to avoid her milk? } & False & 365 & 73.0 \\
\hline & True & 135 & 27.0 \\
\hline \multirow{2}{*}{$\begin{array}{l}\text { Does the child get what he needs from milk in the first 5-10 minutes of Breast- } \\
\text { feeding? }\end{array}$} & False & 300 & 60.0 \\
\hline & True & 200 & 40.0 \\
\hline \multirow[t]{2}{*}{ Does continuous Breast-feeding lead to postpartum depression in the mother? } & False & 370 & 74.0 \\
\hline & True & 130 & 26.0 \\
\hline \multirow[t]{2}{*}{ Are some children allergic to their mothers' milk? } & False & 370 & 74.0 \\
\hline & True & 130 & 26.0 \\
\hline \multirow[t]{2}{*}{ Does Breast feeding lead to future obesity in children? } & False & 435 & 87.0 \\
\hline & True & 65 & 13.0 \\
\hline \multirow{2}{*}{ Should not vitamin D be given to children who breastfeed? } & False & 345 & 69.0 \\
\hline & True & 155 & 31.0 \\
\hline \multirow{2}{*}{ Does modern industrial food contain the same ingredients as breast milk? } & False & 415 & 83.0 \\
\hline & True & 85 & 17.0 \\
\hline \multirow{2}{*}{$\begin{array}{l}\text { Should the child be affected by diarrhea or rehydration, should the mother stop } \\
\text { Breast-feeding? }\end{array}$} & False & 360 & 72.0 \\
\hline & True & 140 & 28.0 \\
\hline \multirow{2}{*}{ Is the larger the size of the breast the more milk contains? } & False & 330 & 66.0 \\
\hline & True & 170 & 34.0 \\
\hline \multirow{2}{*}{ Can a mother who breastfeed her baby cannot dye her hair? } & False & 350 & 70.0 \\
\hline & True & 150 & 30.0 \\
\hline \multirow{2}{*}{ Is it necessary for the mother to stop breast-feeding for 48 hours before X-Ray? } & False & 390 & 78.0 \\
\hline & True & 110 & 22.0 \\
\hline \multirow{2}{*}{$\begin{array}{l}\text { Do you need a prenatal abdominal exercise before labour so you can breastfeed your } \\
\text { baby? }\end{array}$} & False & 430 & 86.0 \\
\hline & True & 170 & 14.0 \\
\hline \multirow{2}{*}{$\begin{array}{l}\text { Does the mother's inability to breastfeed have a relationship with the family to which } \\
\text { she? }\end{array}$} & False & 370 & 74.0 \\
\hline & True & 130 & 26.0 \\
\hline Ders mouth funous logd to hurning moin in the & False & 370 & 74.0 \\
\hline Does mouth fungus lead to burning pain in the chest and dream? & True & 130 & 26.0 \\
\hline & False & 420 & 84.0 \\
\hline Does breast-feeding be harmful to babies? & True & 80 & 16.0 \\
\hline Is a child who hrooctfod noturolly for a lono norind to he gov? & False & 385 & 77.0 \\
\hline Is a child who breastted naturally for a long period to be gay? & True & 115 & 23.0 \\
\hline & False & 370 & 74.0 \\
\hline Are heavy children becoming an obstacle to Breast- feeding? & True & 130 & 26.0 \\
\hline & False & 395 & 79.0 \\
\hline Is the only child advised not to breastfeed naturally? & True & 105 & 21.0 \\
\hline & False & 360 & 72.0 \\
\hline Is the mother who breastfeeds on one hand her son becomes healthier? & True & 140 & 28.0 \\
\hline & False & 370 & 74.0 \\
\hline Is breast-feeding worse mother health? & True & 130 & 26.0 \\
\hline Is there no additional value for breast milk after 12 months so you can stop breast- & False & 305 & 61.0 \\
\hline feeding at this time? & True & 195 & 39.0 \\
\hline & False & 335 & 67.0 \\
\hline Does breast milk become water after 6 months? & True & 165 & 33.0 \\
\hline Doos Droost fooding Inomooc & False & 405 & 81.0 \\
\hline Does Breast feeding Increase Myopia? & True & 95 & 19.0 \\
\hline Con m the who hostonn hroot fodino & False & 300 & 60.0 \\
\hline Can a mother who has stopped breast-feeding cannot breastfeed? & True & 200 & 40.0 \\
\hline & False & 295 & 59.0 .0 \\
\hline Is Bad Nutrition Sufficient Can Breast feeding? & True & 205 & 41.0 \\
\hline Con o mothor not worl with Brooct_foeding? & False & 415 & 83.0 \\
\hline Can a mother not work with Breast-feeding? & True & 85 & 17.0 \\
\hline
\end{tabular}


Table (3): Questions at which myths more than facts

\begin{tabular}{|c|c|c|c|}
\hline & & No. & $\%$ \\
\hline \multirow{2}{*}{$\begin{array}{l}\text { Does the mother feel that her milk is too } \\
\text { little and cause hunger for the baby so she } \\
\text { feeds him artificially? }\end{array}$} & False & 130 & 26.0 \\
\hline & True & 370 & 74.0 \\
\hline \multirow{2}{*}{$\begin{array}{l}\text { Should the mother breastfeed the baby } \\
\text { from both breasts every time you } \\
\text { breastfeed him? }\end{array}$} & False & 190 & 38.0 \\
\hline & True & 310 & 62.0 \\
\hline \multirow{2}{*}{$\begin{array}{l}\text { Should the mother wash her nipples before } \\
\text { Breast-feeding the baby each time? }\end{array}$} & False & 205 & 41.0 \\
\hline & True & 295 & 59.0 \\
\hline \multirow{2}{*}{$\begin{array}{l}\text { Should a smoker's mother not breastfeed } \\
\text { her baby? }\end{array}$} & False & 190 & 38 \\
\hline & True & 310 & 62.0 \\
\hline \multirow{2}{*}{$\begin{array}{l}\text { Does the mother have to drink plenty of } \\
\text { fluids to compensate for the milk that the } \\
\text { child drinks? }\end{array}$} & False & 185 & 37.0 \\
\hline & True & 315 & 63.0 \\
\hline
\end{tabular}

Table (4): Questions at which there is borderline between myths and facts

\begin{tabular}{|c|c|c|c|}
\hline & & No. & $\%$ \\
\hline \multirow{2}{*}{$\begin{array}{l}\text { Can a mother breastfeed her baby not to } \\
\text { take contraceptives? }\end{array}$} & False & 275 & 55.0 \\
\hline & True & 225 & 45.0 \\
\hline \multirow{2}{*}{$\begin{array}{l}\text { Is the stoppage of the baby on his } \\
\text { mother's breast lead to cracks and pain } \\
\text { in the chest? belongs }\end{array}$} & False & 220 & 44.0 \\
\hline & True & 380 & 56.0 \\
\hline \multirow{2}{*}{$\begin{array}{l}\text { Does the child, after four weeks of } \\
\text { childbirth, need to breastfeed only every } \\
4 \text { hours? }\end{array}$} & False & 250 & 50.0 \\
\hline & True & 250 & 50.0 \\
\hline \multirow{2}{*}{$\begin{array}{l}\text { Does the mother need to drink milk to } \\
\text { breast milk? }\end{array}$} & False & 285 & 57.0 \\
\hline & True & 215 & 43.0 \\
\hline \multirow{2}{*}{$\begin{array}{l}\text { Is the mother taking the medication - } \\
\text { whatever its kind - should stop Breast- } \\
\text { feeding her baby? }\end{array}$} & False & 230 & 46.0 \\
\hline & True & 270 & 54.0 \\
\hline \multirow{2}{*}{$\begin{array}{l}\text { Does a child's request for milk mean that } \\
\text { he does not satisfy him? }\end{array}$} & False & 245 & 49 \\
\hline & True & 255 & 51 \\
\hline \multirow{2}{*}{$\begin{array}{l}\text { Does breast-feeding change the shape } \\
\text { and size of the breast? }\end{array}$} & False & 225 & 45.0 \\
\hline & True & 275 & 55.0 \\
\hline \multirow{2}{*}{$\begin{array}{l}\text { Does a Breast-feeding child need more } \\
\text { fluids and food in the summer? }\end{array}$} & False & 230 & 46.0 \\
\hline & True & 270 & 54.0 \\
\hline \multirow{2}{*}{$\begin{array}{l}\text { Does Breast-feeding lead to breast } \\
\text { sagging? }\end{array}$} & False & 225 & 45.0 \\
\hline & True & 275 & 55.0 \\
\hline
\end{tabular}

\section{DISCUSSION}

In this study, majority of the mothers had a sound knowledge and a positive attitude towards breastfeeding, which they put into practice. The majority of women agree with facts that said (range 60\%-80\%): Breast-feeding is not old fashioned, not related to her family \& they disagree with myths said precious baby should not feed breast milk \& nursing with one hand is the best for her baby health. Their milk too little so it make them hungry \& request milk. Stoppage of nursing increases their milk. This statement was found in agreement with Lumbiganon et al. ${ }^{(7)}$ who said that if mothers do not latch her baby on right after birth, do it as soon as possible, frequent skin-to-skin contact and putting her baby to the breast will help to get breast feeding going on. Also Lumbiganon et al. ${ }^{(7)}$ said that almost all mothers produce the right amount of milk for their babies. Breast milk production is determined by how well the baby is latched on to the breast, the frequency of breast-feeding and how well the baby is removing milk with each feeding. Support of breast feeding from health care providers, help at home and staying healthy by eating and drinking well. The amount of breast milk that is produced is timed to meet the infant's needs in that the first milk, colostrum, is concentrated but produced in only very small amounts, gradually increasing in volume to meet the expanding size of the infant's stomach capacity. According to La Leche League International, "Experienced breastfeeding mothers learn that the suckling patterns and 
needs of babies vary. Lumbiganon et al. ${ }^{(7)}$ also said that low milk supply is usually caused by allowing milk to remain in the breasts for long periods of time, or insufficiently draining the breasts during feeds. It is usually preventable, unless caused by medical conditions that have been estimated to affect up to five percent of women. While some mothers believe that drinking many fluids increases milk supply, fluid intake does not affect milk volume. "Drink when thirsty" is advised. They disagree also that nursing worsens their health or they cannot nurse while working and their milk become ineffective and useless after 12 months.

As Reifsnider et al. ${ }^{\left({ }^{(8)}\right.}$ said that there is no evidence that it is more favourable to stop breastfeeding after one year, but there is evidence that breastfeeding up to two years is beneficial for both mothers and children. All mothers and babies are different, so mothers need to determine how long they want to breast feed. Regarding breast-feeding with work, Labarere $\boldsymbol{e} t$ al. ${ }^{(9)}$ said that planning and supportive environment encourage mothers to express milk before leaving for work and when they return. This breast milk can be given to the baby during their absence.

Breast-feeding do not lead to depression or mastalgia if their baby' mouth have fungal, obesity in their baby or milk allergy. In facts according to Reifsnider et al. ${ }^{\left({ }^{(8)} \text {, }\right.}$ many mothers experience discomfort in the first few days after birth when they are learning to breast feed, but the right support with positioning their baby for breast-feeding and making sure their baby is correctly attached to the breast, sore nipples can be avoided. There is great benefit of breast feeding as Greer $\boldsymbol{e t}$ al. (10) said that children who are at risk for developing allergic diseases are defined as at least one parent or sibling having atopy. Atopic syndrome can be prevented or delayed through 4-month exclusive breast-feeding, though these benefits may not persist.

Breast milk increased with nursing or what is called demand and by increasing time of sitting not with scheduled, regular, or short sitting. According to Reifsnider et al. ${ }^{\left({ }^{(8)}\right.}$, there is fact said that during the newborn period, most breast feeding sessions take from 20 to 45 minutes. After one breast is empty, the mother may offer the other breast, some mothers may prefer to start a breast feeding session on the breast which the infant was most recently feeding so as to vary the side on which the infant ends because the strength of the infant's suck usually decreases during the course of one feed.

They do not need to stop feeding before X-ray \& with GE or refuse dying or doing heavy abdominal exercise to nurse their babies, or not to take vitamin D supplementation. This statement is similar to what Tremblay et al. ${ }^{(11)}$ said, a mother does not need to interrupt breast feeding if she has an X-ray, MRI, CT, Angiogram, Ultrasound or Mammogram in general. These examinations do not affect Breast-feeding. Sometimes a radiological contrast dye is used to aid the imaging. These dyes do not require a mother to interrupt breast-feeding.
In facts, Chung et al. ${ }^{(12)}$ said that infants who are exclusively breast fed for the first six months are less likely to die of gastrointestinal infections than infants who switched from exclusive to partial breast-feeding at age of three to four months. Ndikom et al. ${ }^{(13)}$ said that breast-feeding mothers who have adequate amounts of vitamin $\mathrm{D}$ in their bodies can successfully provide enough vitamin $\mathrm{D}$ for their nursing children through breast milk. However, lifestyle changes have led to some women not having enough vitamin D. It is recommended that pregnant and nursing mothers obtain adequate vitamin $\mathrm{D}$ or supplement as necessary. few days.

Colostrum is little \&do not increase only after

Gartner et al. ${ }^{(14)}$ said that the amount of breast milk that is produced is timed to meet the infant's needs. In that, the first milk, colostrum, is concentrated but produced in only very small amounts, gradually increasing in volume to meet the expanding size of the infant's stomach capacity. According to La Leche League International, "Experienced breast feeding mothers learn that the suckling patterns and needs of babies vary.

The majority of women agree with myths that said (range 60\%-75\%): They should nurse by both breasts all the time and wash them every time. Daws ${ }^{(15)}$ said that the infant should empty at least one breast at each feeding; otherwise, the breast will not be stimulated sufficiently to refill. Both breasts should be used at each feeding during the early weeks to encourage maximal milk production. After the milk supply is established, the breasts may be alternated at successive feedings. WHO ${ }^{(16)}$ stated that washing your nipples before breast-feeding isn't necessary. When babies are born, they are already very familiar with their own mother's smells and sounds. The nipples produce a substance that the baby smells and has 'good bacteria' that helps to build babies' own healthy immune system for life ${ }^{(16)}$.

\section{They must drink plenty of fluid to compensate what babies drink.}

Burbidge (17) said that, many mothers feel thirsty when they breast feed, especially when their baby is newborn. It is a good idea to have a glass of water available while breast-feeding, but it's not necessary to drink more than you feel comfortable with, as it doesn't help to increase milk supply and it may be unpleasant. Some women like to drink herbal teas and infusions to increase liquid intake. However, excessive amounts of some herbal teas and infusions can risk depleting milk supply, so they need to be used moderately and with caution.

\section{They need milk to produce milk.}

Human beings are the only animals that consume milk produced by other animals. No other mammalian mothers drink milk, yet they all produce milk perfectly tailored to the needs of their young. Milk is sometimes seen as a source of calcium, but there are 
plenty of other easily available foods such a broccoli, peppers and spinach, which contain even more calcium as well as other nutrients too. In some cultures, people traditionally do not drink milk or eat dairy products at all, yet mothers succeed in breast-feeding their children.

\section{Breast feeder is healthier than artificial feeding.}

Reviews from 2007 by Horta et al. ${ }^{(\mathbf{1 8})}$ reported that there are numerous benefits for breast-feeding that aids general health, growth and development in the infant. Infants who are not breastfed are at mildly increased risk of developing acute and chronic diseases, including lower respiratory infection, ear infections, bacteremia, bacterial meningitis, botulism, urinary tract infection and necrotizing enterocolitis.

\section{Breast-feeding prevent pregnancy.}

WHO stated that exclusive breast-feeding usually delays the return of fertility through lactational amenorrhea, although it does not provide reliable birth control? Breast-feeding may delay the return to fertility for some women by suppressing ovulation. Mothers may not ovulate, or have regular periods, during the entire lactation period. The non-ovulating period varies by individual. This has been used as natural contraception, with greater than $98 \%$ effectiveness during the first six months after birth if specific nursing behaviors are followed ${ }^{(\mathbf{1 9})}$.

They cannot take any medications as long as feeding.

UNICEF stated that it is important to inform her doctor that she is breast-feeding and to read the instructions with any medications she will buy over the counter. It might be necessary to take medications at a specific time or in a specific dosage, or to take an alternative formulation. She should also tell the baby's doctor about any medications that she is taking ${ }^{(20)}$.

Breast milk become useless after 6 months, breastfeeding infant need extra fluid and food in summer.

WHO' guidelines recommend "continued frequent, on-demand breast-feeding until two years of age or beyond". The vast majority of mothers can produce enough milk to fully meet the nutritional needs of their baby for six months.

Breast milk supply augments in response to the baby's demand for milk, while some mothers believe that drinking a lot of fluids increases milk supply, fluid intake does not affect milk volume ${ }^{(21)}$. "Drink when thirsty" is advised. If the baby is latching and swallowing well, but is not gaining weight as expected or is showing signs of dehydration, low milk supply in the mother can be suspected ${ }^{(22)}$.

\section{CONCLUSION}

It is really an encouraging observation that majority of the mothers had good knowledge and a positive attitude towards breast-feeding. Majority of the mothers had fed the baby colostrum. Late initiation of breast-feeding has implications for health education programs and neonatal feeding strategies.

\section{RECOMMENDATIONS}

More effective community educational approaches are needed, perhaps starting in schools and concentrated in antenatal clinics, to prepare expectant mothers to make informed decisions regarding breastfeeding and lactation management. Training of health workers and volunteers should be on counseling rather than just giving words. It should also be on how to breast feed, rather than telling mothers what to do.

Myths and misconceptions should be corrected by using various modes and types of communication. Cooperation should be achieved for providing privacy to nursing mothers in both working and public places. Intensification and promotion by doctors and family members are corner stone for successful breast-feeding.

\section{Financial support and sponsorship: Nil. Conflict of Interest: Nil.}

\section{REFERENCES}

1. World Health Organization et al. (1992): Indicators for assessing breast-feeding practices. Birth, 19: 185189.

2. Rollins N, Bhandari N, Hajeebhoy $\mathbf{N}$ et al. (2016): Lancet Breastfeeding Series Group. Why invest, and what it will take to improve breastfeeding practices? Lancet, 387 (10017): 491-504.

3. Jones J, Kogan M, Singh G et al. (2011): Factors associated with exclusive breastfeeding in the United States. Pediatrics, 128 (6): 1117-1125.

4. Agampodi A, Agampodi T, Piyaseeli U (2007): Breastfeeding practices in a public health field practice area in Sri Lanka: a survival analysis. International Breastfeeding Journal, 2: 13-19.

5. Zhou Q, Younger K, Kearney J (2010): An exploration of the knowledge and attitudes towards breastfeeding among a sample of Chinese mothers in Ireland. BMC Public Health, 10: 722 -730.

6. World Health Organization (2001): Global strategy for infant and young child feeding. Geneva: World Health Organization, Pp: 1-5. https://www.who.int/ nutrition/ publications/infantfeeding/9241562218/en/

7. Lumbiganon $P$, Ruth $M$, Malinee $L$ et al. (2016): Antenatal breast feeding education for increasing breast feeding duration. https://www.researchgate.net/publication/311473809 _Antenatal__breastfeeding _education_for_increasing_breastfeeding_duration

8. Reifsnider E, Gill S, Villarreal P et al. (2003): Breast feeding Attitudes of WIC Staff: A Descriptive Study. The Journal of Perinatal Education, 12: 3-9.

9. Labarere J, Gelbert-Baudino $\mathrm{N}$, Ayral A et al. (2005): Efficacy of breast feeding support provided by trained clinicians during an early, routine, preventive visit: a prospective, randomized, open trial of 226 mother-infant pairs. Pediatrics, 115: 139-146.

10. Greer F, Sicherer S, Burks A (2008): Effects of early nutritional interventions on the development of atopic disease in infants and children: the role of maternal dietary restriction, breastfeeding, timing of 
introduction of complementary foods, and hydrolyzed formulas. Pediatrics, 121 (1): 183-91.

11. Tremblay E, Therasse E, Thomassin-Naggara I et al. (2012): Quality Initiatives: Guidelines for Use of Medical Imaging during Pregnancy and Lactation.RadioGraphics, 32: 897-911.

12. Ip S, Chung $M$, Raman $G$ et al. (2007): Breastfeeding and maternal and infant health outcomes in developed countries. Evid Rep Technol Asses., 153: 1-186.

13. Ndikom C, Fawole B, Roslyn I (2014): Extra fluids for breastfeeding mothers for increasing milk production. The Cochrane Database of Systematic Reviews, (6): CD008758.

14. Gartner L, Morton J, Lawrence $\mathrm{R}$ et al. (2005): Breastfeeding and the use of human milk. Pediatrics, 115 (2): 496-506.

15. Daws D (1997): The perils of intimacy: Closeness and distance in feeding and weaning. Journal of Child Psychotherapy, 23 (2): 179-199.

16. World Health Organization (1991): Indicators for Assessing Breastfeeding Practices. Pp: 14. https://www.who.int/

maternal_child_adolescent/documents/cdd_ser_91_1 4/ en/
17. Burbidge A (2019): Breastfeeding and a Mother's Diet: Myths and Facts. https://www. laleche.org.uk/ breastfeeding-and-a-mothers-diet-myths-and-facts/

18. Horta B, Bahl R, Martinés J et al. (2007): Evidence on the long-term effects of breastfeeding: Systematic reviews and meta-analysis. http://whqlibdoc.who.int/ publications/2007/9789241595230_eng.pdf

19. World Health Organization Department of Reproductive Health and Research (2009): Progesterone-only contraceptive use during lactation and its effects on the neonate.Available from: http://www.who. int/ reproductivehealth/publications/family_planning/en/

20. WHO/UNICEF (2003): Global strategy for infant and young child feeding. http://www.who.int/child_adolescent_health/ documents/9241562218/en/index.html

21. World Health Organization (2003): Global strategy for infant and young child feeding (PDF). https://apps.who.int/.../9241562218.pdf; sequence=1

22. Jeong G, Park S, Lee Y et al. (2017): Maternal food restrictions during breastfeeding. Korean Journal of Pediatrics, 60 (3): 70-76. 